\title{
DEVELOPING A LOCAL SEMI-MECHANICAL INCUBATOR FOR MINIMUM PRODUCTION COST
}

\begin{abstract}
Abd El-Mottaleb , A. F.*
ABSTRACT

A local semi-mechanical incubator was developed to hatch some kinds of poultry eggs with the purpose of decreasing egg losses and increasing incubation efficiency.

A comparative study was conducted on the performance of the incubator before and after development. Performance was investigated as a function of change in temperature, relative humidity, number of turns and kind of egg in terms of hatching ratio, loss ratio and hatching cost.

Experimental results revealed that hatching ratio and hatching cost were in the optimum range with the use the developed incubator under the following conditions :

- Temperature of about 37.5 C , relative humidity of about $55 \%$ and number of turns of 12 times per day.

- Improvements lead to of increasing of safety factors and professional integrity for laborer and detecting any shortcoming in components of the incubator electricity circuit
\end{abstract}

\section{INTRODUCTION}

The poultry production reaches now $20.1 \%$ from animal production and stands for $64.1 \%$ from overall agricultural national income.

The major incubation problems decreased due to increased ratio of incubation processes in local semi - mechanical incubators. The major incubation problems include early embry death, the early or late incubation adhension, the abnormal state, fast respiration and lax chickens. There are many factors that control the performance of incubator. These factors include incubator type, size, source of power and environmental variables including humidity, temperature and aeration .

Hegazy (2000) noted that large scale hatcher equipment with various

*-Senior Rese., Agric . Eng . Ins ., Dokki, Giza , Egypt . 
types of automated or semi automated artificial incubator are operating in Egypt now, either by the government or by private enterprise, and small artificial incubators are locally made and increasingly used by nascent specialist poultry keepers, despite their relative inefficiency in hatchability.

Philadelphia and Febiger (2000) found that in forced-air incubators, humidity in the incubator varies from 83 to $88^{\circ} \mathrm{F}$. ( 28 to $31 \mathrm{C}^{\circ}$ wet bulb), depending on the type of eggs incubated . This level of humidity is maintained until the last 3 or 4 days before hatching. At this time, the humidity is increased to $90-95{ }^{\circ} \mathrm{F}$ ( $32-35 \mathrm{C}^{\circ}$ wet bulb). Wet-bulb thermometers are checked regularly to be sure that the bulb is covered with a wet wick. Dry bulb temperature in forced draft incubators, should be between 99.5 and $100{ }^{\circ} \mathrm{F}\left(37.5-37.8^{\circ} \mathrm{C}\right)$ with a wet bulb temperature of 83 to $87{ }^{\circ} \mathrm{F}\left(28.3-30.5^{\circ} \mathrm{C}\right)$. Eggs should be set large end up and turned hourly, or more often, during the first 14 days of incubation but never after 18 days of incubation.

Harun et al. (2001) studied artificial incubation of Muscovy duck eggs. The results obtained in this study indicate that the best incubation temperature was $37.5^{\circ} \mathrm{C}$.

Fasenko et al. (2001) used 3600 British united turkey hatching eggs in two separate trials to test whether Presto Rage Incubation (PRESI) treatments of 0,6 and 12 hours (Trial 1) or 0,7 and 14 hours (Trial 2) could improve the hatchability of eggs stored $\left(17^{\circ} \mathrm{C}\right)$ for 14 versus 4 day. The development of the embryos $(n=30)$ was staged before and after exposing eggs to the various PRESI treatments. Embryonic development was also established after storage to ascertain whether embryonic development was occurring during storage. The remaining eggs in each trial were split into three groups $(\mathrm{n}=500)$ and incubated for 28 days to examine embryonic mortality and hatchability. No changes were observed in embryonic development due to egg storage. Embryos were significantly more developed as the number of PRESI hours increased. Therefore, embryos from different PRESI treatments were placed in storage at differed stages of development. Early mortality (1 to 7 days incubation), mortality at internal and external pepping, and hatchability of 
fertile eggs significantly reduced eggs stored for 14 versus 4 days. The various PRESI treatments did not significantly affect the mortality or hatchability of eggs stored | for 4 days. However, the hatchability of eggs incubated prior to storage for 12

( hours and then storage for 14 days was restored to the levels reported for eggs subjected to the treatment that represents the Indus norm $(0 \mathrm{~h}$ of PRESI and 4 day storage). These results found that embryos of eggs stored for 14 days, which have developmentally advanced to the stage of complete hypobl formation (PRESI for 12 hours), have a survival advantage over eggs stored for 14 days that have not been subjected to any PRESI

Elibol and Brake (2003) found that hatching eggs from broiler breeder flocks at $37,41,59$ and 63 week age were stored for 1 or 2 day at $38{ }^{\circ} \mathrm{C}$ and $55 \mathrm{RH}$ and then turned 24, 48 or 96 times per day from 3 to 11 days of incubation. All eggs were turned 24 times per day from 1 to 2 days and 12 to 18 days of incubation. Fertile hatchability was better at 37 and 41 weeks of age than at 59 and 63 weeks age due primarily to increased early dead embryos. Fertile hatchability was increased by turning 96 times per day compared to either 24 or 48 times per day. This improvement was due to a reduction in late embryonic mortality. There was no significant interaction of flock age $\mathrm{x}$ turning in storage for fertile hatchability or embryonic mortality.

Shaapan (2004) found that for poultry eggs in the mechanical incubators with strong air, the highest hatching ratio was $85 \%$ at 37.2 ${ }^{\circ}$ C.Meanwhile, in the semi mechanical incubators with strong air, the best temperature was $37.6{ }^{\circ} \mathrm{C}$, where loss ratio of poultry eggs was $5 \%$, and the highest hatching ratio was $71.1 \%$.

Morad et al. (2008) studied the effect of some operating parameters on the performance of two incubators ( local and developed) during hatching different kinds of poultry eggs. Performance was experimentally investigated as a function of change in temperature, humidity, turning number, kind of egg and light regime in terms of hatching ratio, loss ratio and hatching cost . The experimental results revealed better hatching ratio of maximum (90\%), while both of loss ratio (12) \% and hatching cost (1.15 L.E /Chicken ) were minimum, under the following conditions : 
temperature $37.5 \circ \mathrm{C}$, humidity $55 \%$ and turns 12 per day under dark regime .

Horbanczuk et al. (2009) incubated 240 Ostrich eggs divided into 4 batches each of 60 eggs in multistage incubator at dry bulb temperature of $36.5{ }^{\circ} \mathrm{C}$ and initial $\mathrm{RH}$ of $50,40,30$, and $25 \%$. The overall hatchability was $54 \%$ of eggs set and $76 \%$ of fertile eggs. The hatchability was $65,72,75$, and $82 \%$ at $50,40,30$, and $25 \%$ initial $\mathrm{RH}$ respectively. Weight loss during incubation ranged from $10.18 \%$ at $50 \%$ $\mathrm{RH}$ to $13.51 \%$ at $25 \% \mathrm{RH}$. Eggs from the batch incubated at the highest initial RH $50 \%$ had the greatest number of mal positioned chicks and most chicks with un-absorbed yolk sacs, and the one day-old chicks that hatched had poorer viability than chicks from other groups. It was suggested that wide range of $\mathrm{RH}$ (25 to $40 \%$ ) can be used in the incubation of Ostrich eggs provided that egg weight, egg shell thickness and porosity are taken into account.

The objectives of this research are: developing a local semi-mechanical incubator to be suitable for local production and optimizing some parameters affecting the performance of the developed incubator .

\section{MATERIALS AND METHODS}

The main experiments were carried out during seasons of 2008 / 2009 at a small private project to develop a local semi-mechanical incubator, to overcome the problems noticed during case study for incubator through advocating technological solutions for small scale projects for the youth , with the American University in Cairo , Partnership in Development Research Youth Project.

\section{2a-Materials :-}

\section{- Local semi- mechanical incubator before development :-}

All experiments were conducted using a local semi- mechanical incubator which had the following speafications :-

Type : local, capacity: 1000 eggs per hatching cycle, hatching chamber eggs trays , electric heater, fan, water pan hygrometer . and thermostat ; as shown in fig . (1) 


\section{- Hatching chamber:}

The hatching chamber is formed from single-ply wood .The thickness of the wooden wall was $1.5 \mathrm{~cm}$. Its dimensions were 50x80x120m.

\section{- Egg trays:}

Ten egg trays were constructed inside the hatching chamber. Hundred eggs were put on each tray during the hatching period ( 21 days).

\section{- Electric heater:}

Heat is supplied inside the hatching chamber by an electric heater .

\section{- Thermostat:}

The thermostat adjusts the temperature inside the hatching chamber in the range of the required values .

\section{- Water pan:}

A water pan with dimensions of $30 \mathrm{X} 30 \mathrm{X} 10 \mathrm{~cm}$ is put inside the hatching chamber in front of a fan to adjust relative humidity in the range of the required values .

\section{- Hygrometer:}

Hygrometer is put inside the hatching chamber in order to continuously measure humidity values.

Egg turning is done manually in local semi-mechanical incubator by tilting eggs to angles 45,45 on both sides, 6 times / day, while natural ventilation is used through two openings in the hatching chamber.

\section{2c1. Before modification:}

the incubator walls comprised a single - ply wood of $2.5 \mathrm{~cm}$ thickness . To improve thermal insulation, another wall of the Same material and thickness was added to the outside. An insulating material (glass wood) of $5 \mathrm{~cm}$ thickness was added in between the two walls.

\section{2c2. Solving the problems of heating system:}

Solving the problems of heating system is conducted by modifying a wire heater enclosed in a tight bowl of oil, with seal weld so as not to leak any oil fumes inside the incubator. The heater in the oil leads to increase the radiating surface to prevent the fluctuation of heat and electricity and maintains a constant temperature for a longer period. Oil containers of 
different sizes can also be used to match with the incubator volume, and connect with a thermostat (figure 3 ).

\section{2c3. Solving the problem of power failures :}

Electricity circuit was modified as follows:

- Incubator electricity circuit was supplemented by secondary battery 12 volt and capacity of more than 70 Ampere.h.

- On the other hand, the battery charger is connected as shown in fig (3)

By the above solutions, the following features were achieved:

- Voltage fluctuation of the main source of the temperature inside the incubator is reduced.

- If the power of the main source goes out, the battery is the standby source for heater for not less than 6 hours, which can be increased by increasing the battery capacity.

- This modification is totally safe in the incubator operation for a worker, when there is any defect in the electrical components of the incubator, because all the components were working under 12 volts (battery voltage) .

\section{2c4. Solving the problem off egg turning :-}

The manual turning system in the local incubator is developed to be mechanical as follows :-

a) The holder of the eggs tray was replaced with a trolley that could replace the tray with suitable linkage to change the egg- tilting angle (Fig - 4) .

b) Source of movement motor 12 volt (50 Watt) was used with speed reduction (Timer 12-hour) and 2 microswitches to determine the movement stroke in both directions (turning angle 45) as shown in fig (4) .

2c5. Solving the problem of fluctuations in relative humidity in the incubator:

- Modified water pan (source of humidity) was put inside the incubator to increase or decrease the water surface to suit the incubator size with a sliding cover. This can handle and control the water surface or close it completely. Measuring the relative humidity was by a hygrometer, as shown in fig. (5). 

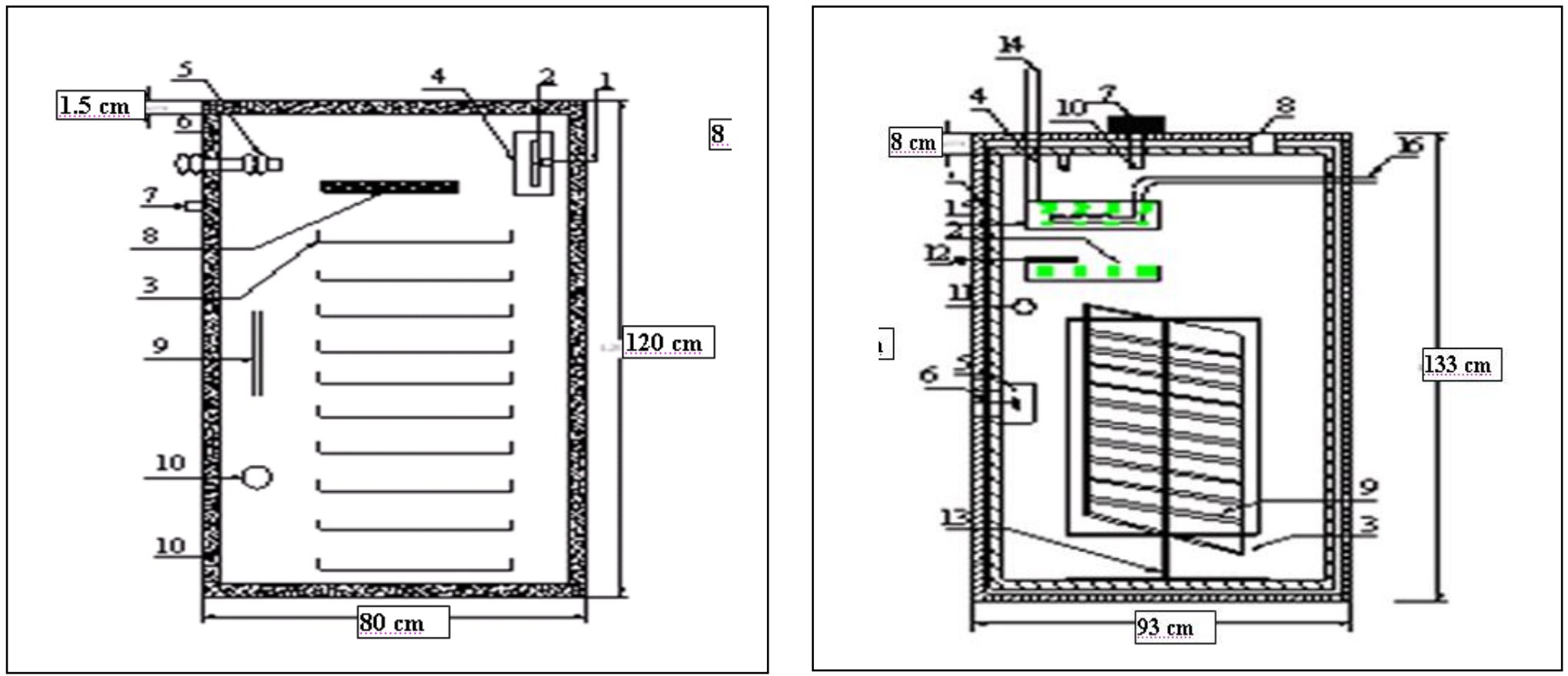

Fig.1: Semi-mechanical incubator before development.

1-Vent 2- Fan 3- Eggs tray

5- Mechanical thermometer

8-Water pan 9-Thermometer

11-One strip wood wall . 6-vent 7-Light

10- Hygrometer

Fig.2: Semi-mechanical incubator after development

$\begin{array}{lcc}\text { 1-Double insulation wall } & \text { 2-Water pan } & \text { 3- Hatcher box } \\ \text { 4-Light } & \text { 5- Fan + electric power } & \text { 6- Vent } \\ \text { 7-Digital thermometer } & \text { 8-Vent } & \text { 9-Egg trays } \\ \text { 10-Temperature sensor } & \text { 11-Hygrometer } & \text { 12-Hand to remove } \\ \text { 13- Head holder of the trolly } & \text { 14- Tube of oil raiser } \\ \text { 15- Oil and heater bowl } & \text { 16- To electric mains }\end{array}$

1-Double insulation wall 2-Water pan 3-Hatcher box

15- Oil and heater bow

Misr J. Ag. Eng., July 2010 
- Two air vents were added to the old system to control air entry. Another two small 12-V electric fans were also added for better distribution of air inside the incubator as shown in fig.2.

\section{2d. Methods}

Experiments were conducted to optimize some parameters affecting the performance of the local semi- mechanical incubator before and after development, during hatching some of poultry eggs. These parameters are: four incubation temperatures of $37.0,37.2,37.5$, and $37.9 \mathrm{C}^{\circ}$, Four relative humidities (RH) of 50, 55, 60, and $65 \%$, four turning times 4,6,8,12 and 24 per day carried out manually in the local incubator and automatically in the incubator after development. Three kinds of eggs (Balady, Mandaraa, Enshass) were used.

\section{2e. Measurements:}

\section{2e.1. Hatching ratio:}

Hatching ratio, $\%=(\mathrm{H} / \mathrm{T}) \times 100$

Where:

$\mathrm{H}=$ Number of hatched chicks in the sample.

$\mathrm{T}=$ Total number of the sample.

\section{2e.2. Loss ratio:}

Loss ratio, $\%=(\mathrm{D} / \mathrm{T}) \times 100$

Where:

$\mathrm{D}=$ Number of unhatched eggs, death and abnormal chicks in the sample.

\section{2e.3. Hatching cost:}

The costs of performing the hatching operation are estimated according to the conventional way of estimating both fixed and variable costs.

\section{RESULAT AND DISCUSSION}

\subsection{The relationship between hatching temperature and hatching ratio} for local semi mechanical incubators before and after development using different kinds of eggs:-

Fig (6) shows the relationship between the hatching temperature and hatching ratio at relative humidity of $55 \%$, for both local incubator before and after development. 


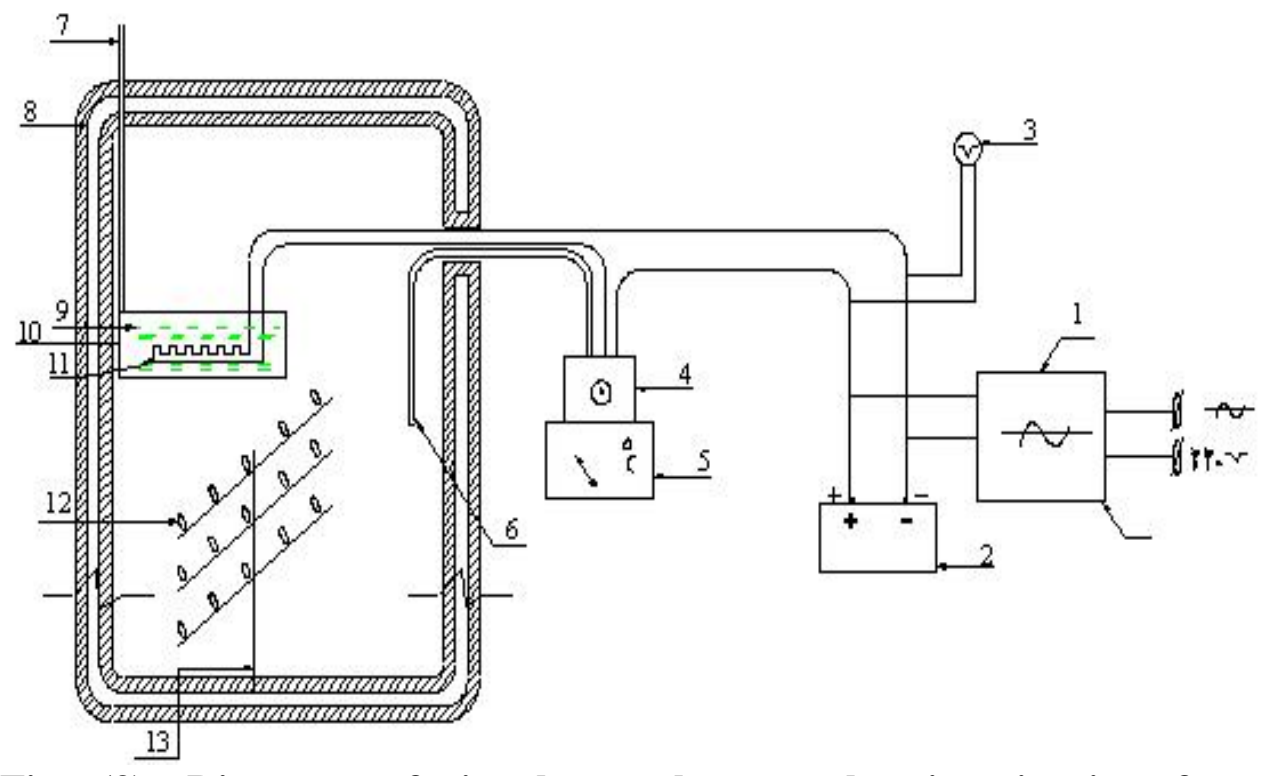

Fig (3) Diagram of incubator heater electric circuit after development.

1 - Charging unit ( 20 amperes ) 7 - Tube to allow oil expansion

2 - Battery capacity ( 70 amperes.h ) 8 - Double insulation wall

3 - Voltameter 15-20 V DC 9 - Oil level of the heater

4 - Thermostat 10 - Oil and heater bowl

5 - Thermometer 11 - Heating element

6 - Temperature sensor 12 - Egg tray

13 - Head of the trolly. 


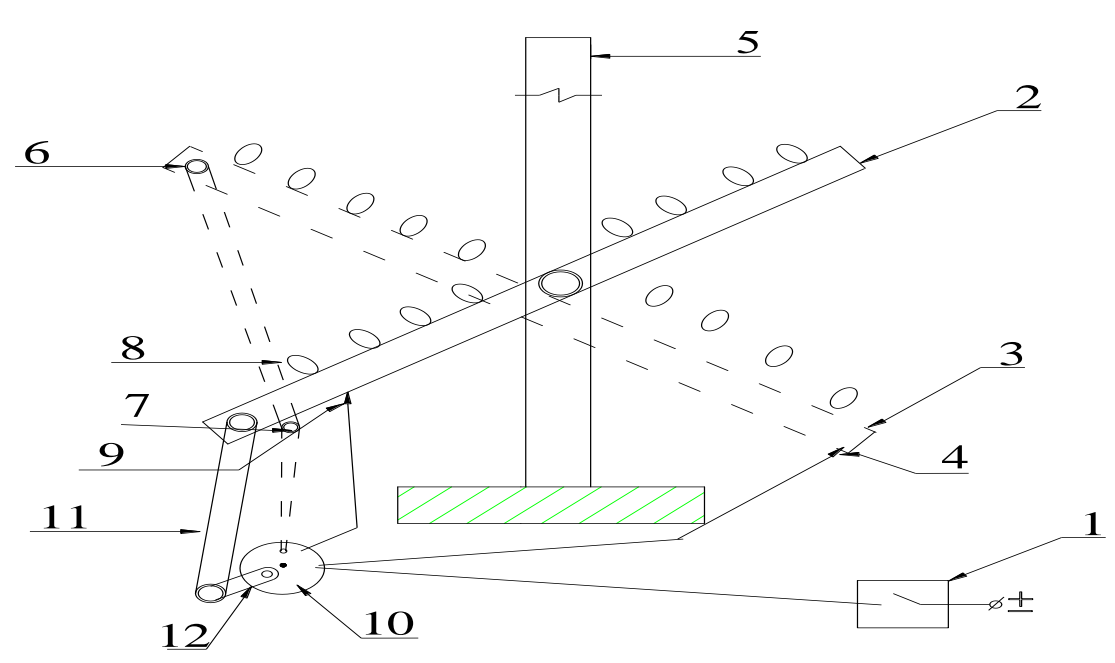

Fig.4.: Diagram of incubator turning system after development.

1 - Timer $12 \mathrm{~V}(12)$.

2 - Egg tray ( angles $45^{\circ}$ ).

3 - Egg tray ( angles $45^{\circ}$ ) reverse direction.

4 - Switch.

5 - Head stand of the trolly.

6 - Connecting rod end.
7 - Connecting rod end..

8 - Eggs .

9 - Switch to reverse direction.

10 - $12 \mathrm{~V}$ (50 watt) motor.

11 - Connecting rod.

12 - Crank.

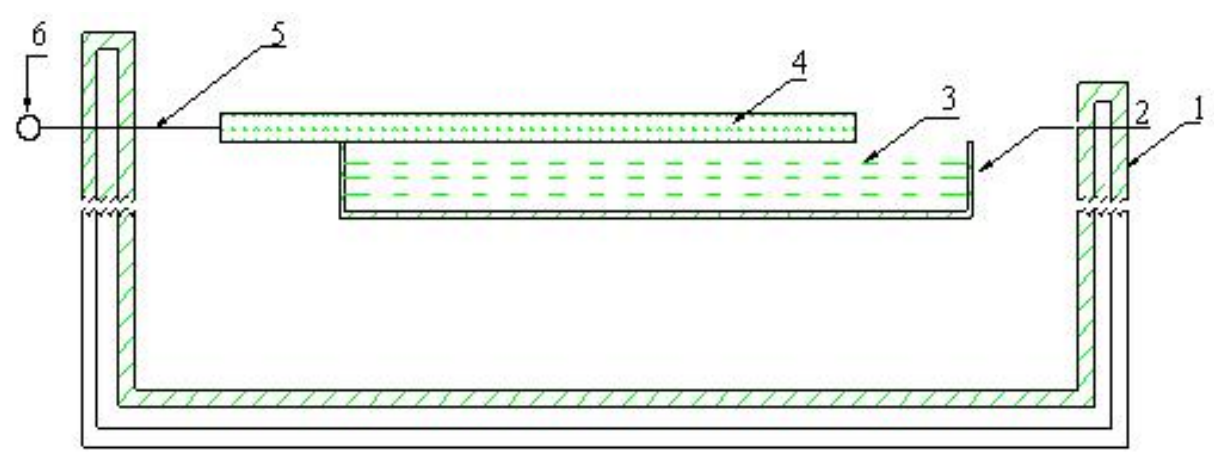

Fig. 5.: Water pan of incubator after development.

1 - Incubator double insulation wall. 4 - Movable cover .

2 - Water pan. 3 - Water. 5 - Hand to move the metal cover. 
Concerning the local incubator before development, data show that hatching ratio values in Balady eggs were $54 \%, 60 \%, 68 \%$, and $56 \%$ at hatching temperatures of $37.0{ }^{\circ} \mathrm{C}, 37.2{ }^{\circ} \mathrm{C}, 37.5{ }^{\circ} \mathrm{C}$, and $37.9{ }^{\circ} \mathrm{C}$, respectively. Mean while hatching ratio values in Mandaraa eggs were 58 $\%, 63 \%, 70 \%$, and $58 \%$, Also the hatching ratio values in Enshass eggs were $65 \%, 68 \%, 72 \%$, and $68 \%$ under the same previous conditions. Relating to the local incubator after development, data show that hatching ratio values in Balady eggs were $63 \%, 68 \%, 71 \%$, and $65 \%$ at hatching temperatures of $37.0{ }^{\circ} \mathrm{C}, 37.2{ }^{\circ} \mathrm{C}, 37.5^{\circ} \mathrm{C}$, and $37.9{ }^{\circ} \mathrm{C}$, respectively. The hatching ratio values in Mandaraa eggs were $70 \%, 73 \%, 82 \%$, and 72 $\%$. Also the hatching ratio values in Enshass eggs were $75 \%, 80 \%, 90$ $\%$, and $85 \%$ under the same previous conditions. The results show that the optimum hatching temperature was $37.5^{\circ} \mathrm{C}$, and the best kind of eggs was Enshass. With decrease of the hatching temperature less than 37.5 ${ }^{\circ} \mathrm{C}$, the chicks will hatch later and cause deformed chicks. With increase in hatching temperature more than $37.5^{\circ} \mathrm{C}$, the chicks will hatch early and cause embryonal death, weak and small chicks.

\subsection{The relationship between hatching temperature and loss ratio for local semi- mechanical incubator before and after development using different kinds of eggs:}

Fig (7) shows the relationship between the hatching temperature, and loss ratio at relative humidity of $55 \%$ for local incubator before and after development. Concerning the local incubator before development, data show that loss ratio values in Balady eggs were $51 \%, 45 \%, 39 \%$, and $48 \%$ at hatching temperatures of $37.0{ }^{\circ} \mathrm{C}, 37.2{ }^{\circ} \mathrm{C}, 37.5{ }^{\circ} \mathrm{C}$, and $37.9{ }^{\circ} \mathrm{C}$ respectively. Meanwhile, loss ratios in Mandaraa eggs were $48 \%, 42 \%$, $37 \%$, and $47 \%$. Also, the loss ratios in Enshass eggs were $39 \%, 37 \%$, $32 \%$, and $34 \%$ under the same previous conditions. Regarding to the local incubator after development, data show that loss ratio values in Balady eggs were $38 \%, 35 \%, 30 \%$, and $36 \%$ at hatching temperatures of $37.0^{\circ} \mathrm{C}$,

$37.2{ }^{\circ} \mathrm{C}, 37.5{ }^{\circ} \mathrm{C}$, and $37.9{ }^{\circ} \mathrm{C}$, respectively. The loss ratio values in Mandaraa eggs were $32 \%, 28 \%, 19 \%$, and $31 \%$. Also, the loss ratio values in Enshass eggs were $28 \%, 22-\%, 12 \%$, and $18 \%$ under the same previous conditions. The results show that the optimum hatching 
temperature was $37.5^{\circ} \mathrm{C}$ because this temperature caused the lowest loss ratio and the highest hatching ratio.
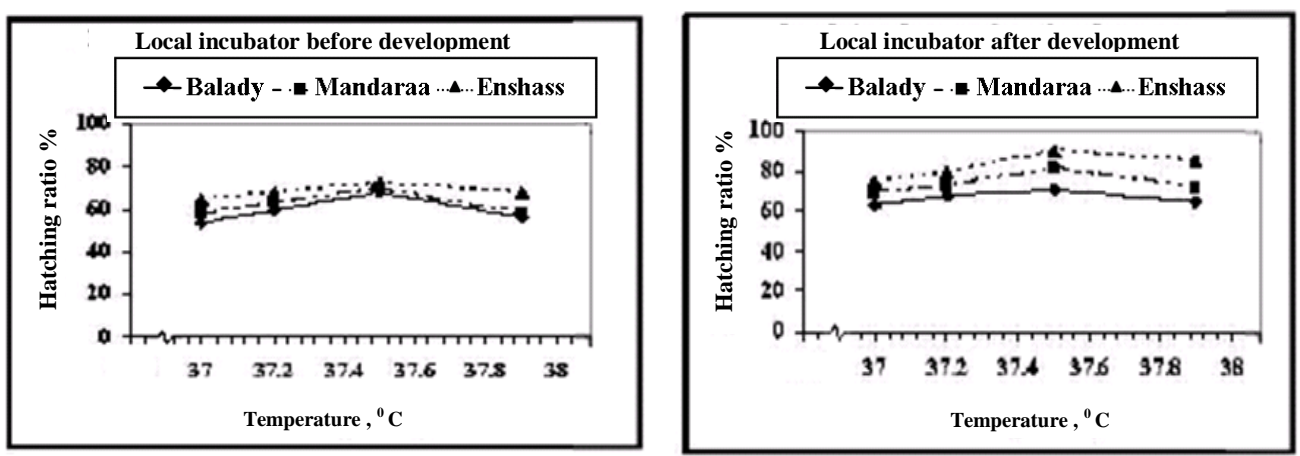

Fig. (6): Relationship between hatching temperature and hatching ratio for local semimechanical incubators before and after development using different kinds of eggs.
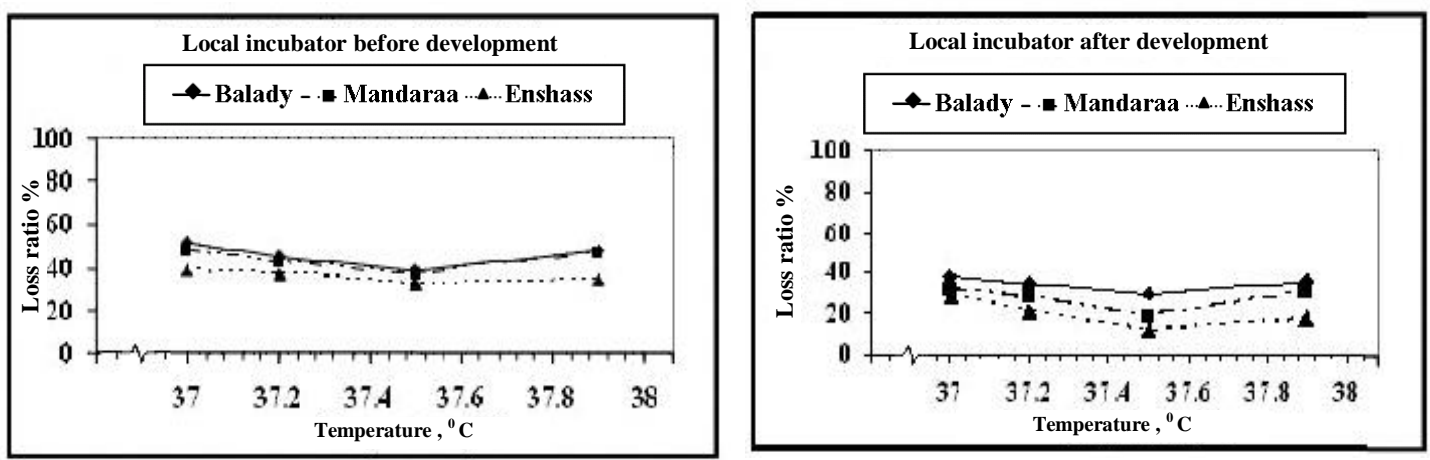

Fig. (7): Relationship between hatching temperature and loss ratio for local semi mechanical incubators before and after development using different kinds of eggs.

\subsection{The relationship between relative humidity and hatching ratio for local semi- mechanical incubator before and after development using different kinds of eggs:}

Fig.8. Shows the relationship between the humidity and hatching ratio at temperature of $37.5^{\circ} \mathrm{C}$ for local incubator before development. Data show that hatching ratio values in Balady eggs were $65 \%, 68 \%, 64 \%$, and $54 \%$ at relative humidities of $50 \%, 55 \%, 60 \%$, and $65 \%$, respectively. 
Meanwhile, hatching ratio values in Mandaraa eggs were $68 \%, 70 \%, 66$ $\%$, and $57 \%$. Also, the hatching ratio values in Enshass eggs were $69 \%, 72$ $\%, 68 \%$, and $64 \%$ under the same previous conditions. With regard to the local incubator after development, data show that hatching ratio values in Balady eggs were $67 \%, 71 \%, 69 \%$, and $60 \%$ at hatching relative humidities of $50 \%, 55 \%, 60 \%$, and $65 \%$, respectively. Meanwhile, hatching ratio values in Mandaraa eggs were $79 \%, 82 \%, 75 \%$, and $67 \%$. Also, the hatching ratio values in Enshass eggs were $85 \%, 90 \%, 78 \%$, and $7 \%$ under the same previous conditions. The results show that the optimum hatching relative |humidity was $55 \%$, and the best kind of eggs was Enshass. This relative humidity point is considered suitable to peel during the incubation that increases the vitality of fetus during the hatching and increase the hatching ratio. If the $(\mathrm{RH})$ becomes more than $55 \%$ during the first incubation (18 days), softness of the peel will occur, that decreases oxygen necessary for the growth of the fetus and this means the death or less vitality of the fetus resulting in a decrease in hatching ratio in this stage. After 18 days stage, the (RH) must be increased from $55 \%$ to $80 \%$ to help the chicken to break the peel easily and come out of the egg, and this helps increasing hatching ratio
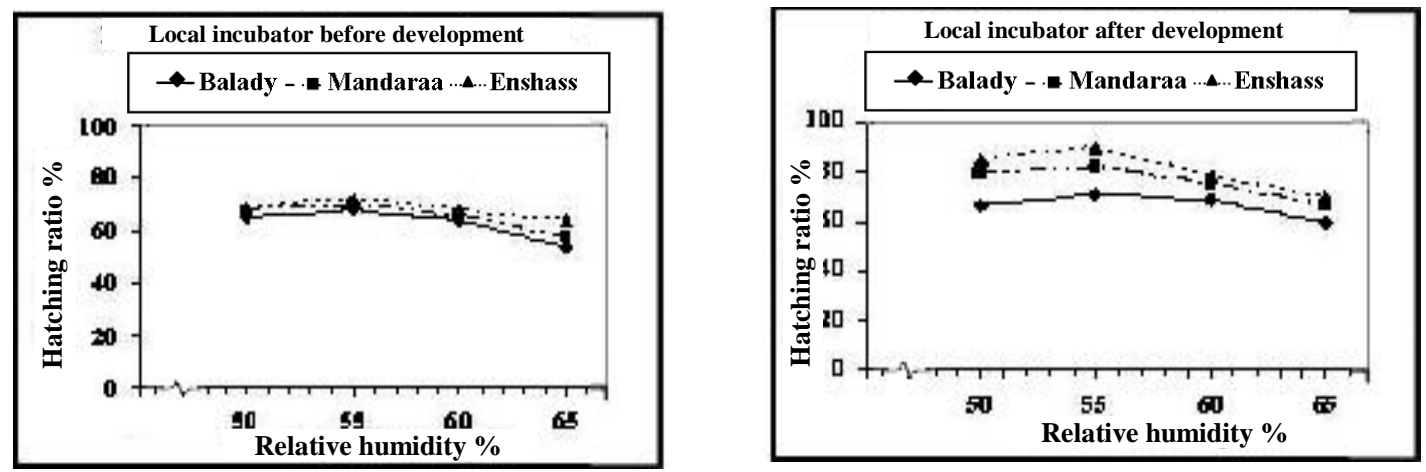

Fig. (8): Relationship between relative humidity and hatching ratio for local semi- mechanical incubator before and after development using different kinds of eggs.

\subsection{The relationship between relative hunlidity and loss ratio for local semi-mechanical incubator before and after development using different} kinds of eggs:

Fig.(9) shows the relationship between the hatching relative humidity and loss ratio at temperature of $37.5{ }^{\circ} \mathrm{C}$ for local incubator before and after 
development. Data show that loss ratio values in Balady eggs were $42 \%, 39$ $\%, 43 \%$, and $50 \%$ at hatching relative humidities of $50 \%, 55 \%, 60 \%$, and $65 \%$, respectively. Meanwhile, loss ratio values in Mandaraa eggs were $40 \%, 37 \%, 41 \%$, and $47 \%$. Also the loss ratio values in Enshass eggs were $33 \%, 32 \%, 35 \%$, and $39 \%$ under the same previous conditions. Considering the local incubator after development data show that loss ratio values in Balady eggs were $35 \%, 30 \%, 39 \%$, and $43 \%$ at hatching relative humidities of $50 \%, 55 \%, 60 \%$, and $65 \%$, respectively. Meanwhile, loss ratio values in Mandaraa eggs were $22 \%, 19 \%, 33 \%$, and $36 \%$. Also, the loss ratio values in Enshass eggs were $16 \%, 12 \%, 25 \%$, and $34 \%$ under the same previous conditions.
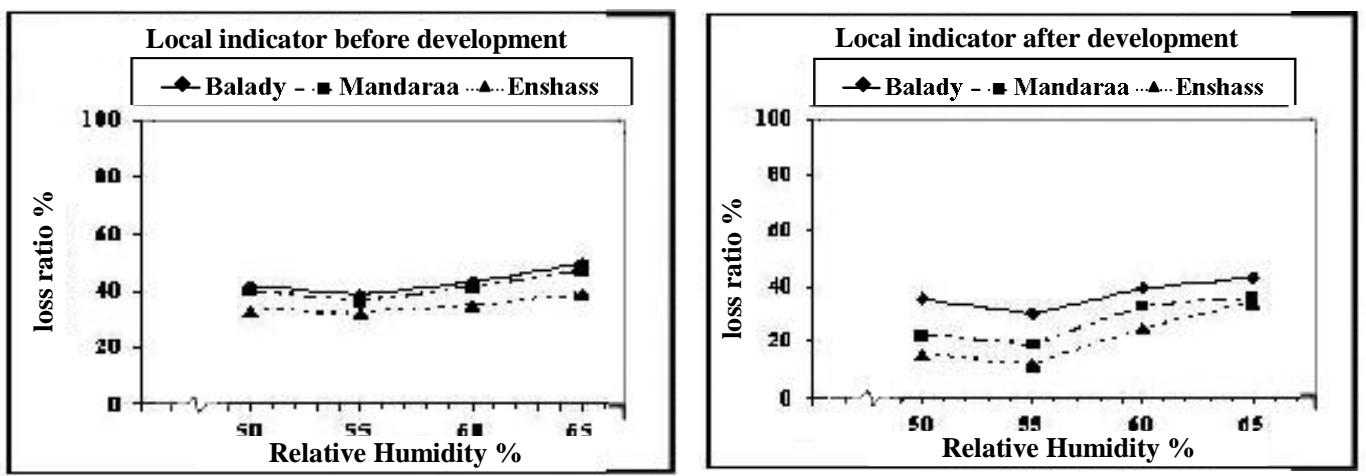

Fig. (9): Relationship between relative humidity and loss ratio, for local semimechanical and developed incubator before and after development using different kinds of eggs.

\subsection{The relationship between turning times and hatching ratio for local semi - mechanical incubator before and after development using different kinds of eggs:}

Fig (10) shows the relationship between the turning times/day and hatching ratio at relative humidity of $55 \%$ and temperature of $37.5{ }^{\circ} \mathrm{C}$ for the local incubator before development, Data show that hatching ratio values in Balady eggs were $50 \%, 68 \%, 61 \%, 42 \%$, and $15 \%$ at turning times/day of $4,6,8,12$, and 24 , respectively. Mean while hatching ratio values in Mandaraa eggs were $59 \%, 70 \%, 64 \%, 46 \%$, and $18 \%$. Also, the hatching ratio values in Enshass eggs were $63 \%, 72 \%, 67 \%, 48 \%$, and $21 \%$ under the same previous conditions. Relating to the local 
incubator after development, data show that hatching ratio values in Balady eggs were $63 \%, 68 \%, 70 \%, 71 \%$, and $62 \%$ at turning times of $4,6,8,12$, and 24 times per day respectively. The hatching ratio values in Mandaraa eggs were $66 \%, 70 \%, 76 \%, 82 \%$, and $71 \%$.

Also, the hatching ratio values in Enshass eggs were $12 \%, 80 \%, 84 \%$, $90 \%$, and $82 \%$ under the same previous conditions. The results show that optimum manual turning in local incubator before development is 6 times per day and the optimum turning number in local incubator after development is 12 times per day. Also the Enshass egg is the best kind that gives the highest hatching ratio.
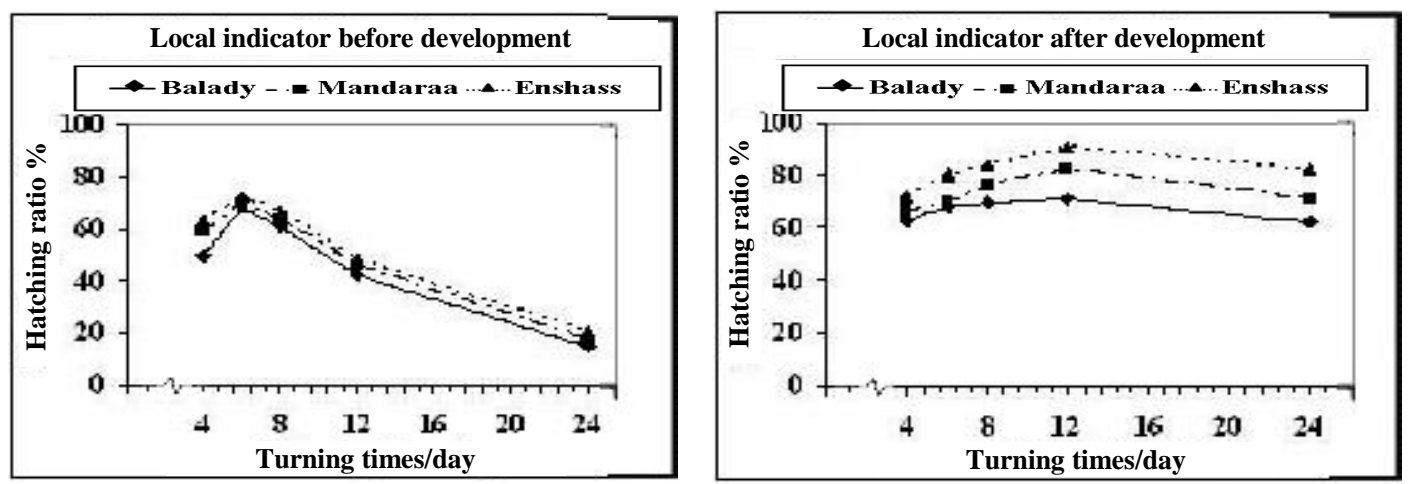

Fig. (10): Relationship between turning times/day and hatching ratio for local semi - mechanical incubator before and after development using different kinds of eggs.

\subsection{The relationship between turning times/day (TTD) and loss ratio for local semi - mechanical incubator before and after development using different kinds of eggs}

Fig (11) shows the relationship between the turning number and loss ratio at relative humidity of $55 \%$, and temperature of $37.5{ }^{\circ} \mathrm{C}$ for local incubator before development. Data show that loss ratio values in Balady eggs were $53 \%, 39 \%, 42 \%, 67 \%$, and $89 \%$ at T.T.D of 4, 6, 8, 12, and 24 , respectively. Meanwhile, loss ratio values in Mandaraa eggs were 44 $\%, 37 \%, 39 \%, 61 \%$ and $86 \%$. The loss ratio values in Enshass eggs were $40 \%, 32 \%, 35 \%, 57 \%$, and $82 \%$ under the same conditions. Relating to the local incubator after development, data show that loss ratio values in Balady eggs were $41 \%, 39 \%, 32 \%, 30 \%$, and $42 \%$ at 
T.T.D of $4,6,8,12$, and 24 , respectively. The loss ratio values in Mandaraa eggs were $37^{\circ}$ o, $32 \%, 26 \%, 19 \%$, and $31 \%$. Also, the loss ratio values in Enshass eggs were $31 \%, 23 \%, 20 \%, 12 \%$, and $28 \%$ under the same conditions. The results show that increasing or decreasing T.T.D than 6 times per day in local incubator before development and 12 times per day in local incubator after development, caused a decrease in hatching ratio and an increase in loss ratio.
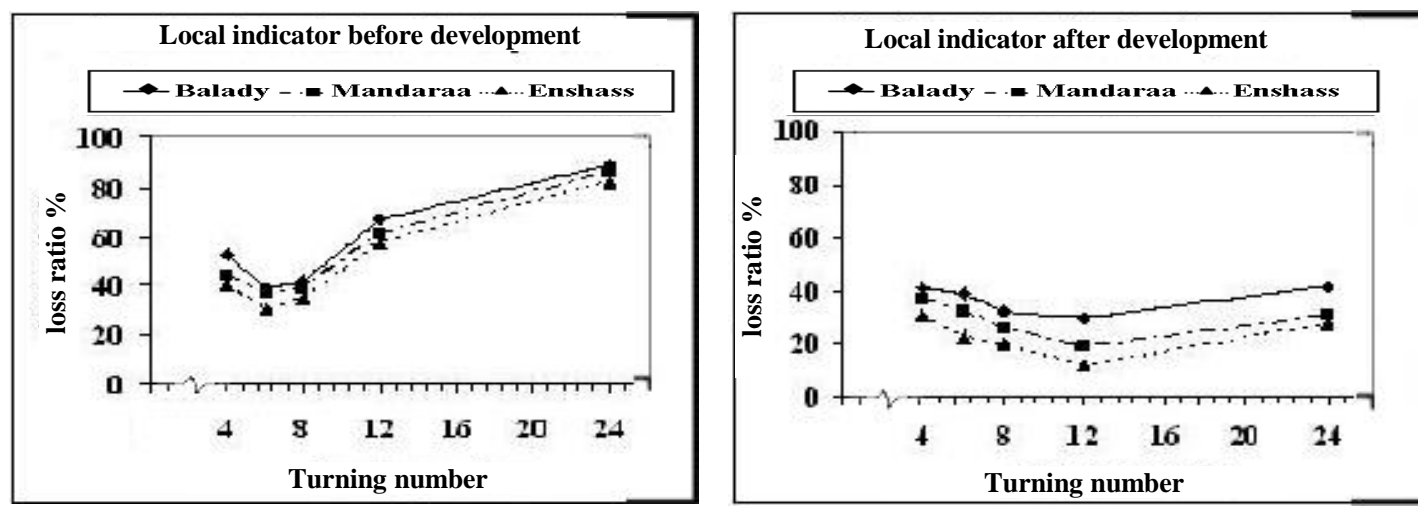

Fig. (11): Relationship between turning number and loss ratio by local semimechanical incubator before and Before development using different kinds of eggs.

\subsection{Hatching cost for local semi-mechanical incubator before and after development:}

Fig (12) shows the hatching cost values with the use of local incubator before development. Data show that hatching cost values were 1.6, 1.48, and 1.37 L.E./chick using Balady, Mandaraa, and Enshass eggs respectively. As to the local incubator after development, data show that hatching cost values were 1.4, 1.25, and 1.15 L.E./chick under the same previous kinds of eggs. The previous data show that minimum hatching cost values were obtained under the use of the local semi- mechanical incubator after development with Enshass eggs.

\section{4- CONCLUSION}

The experimental results reveal that the use of the local incubator after development at a temperature of $37.5^{\circ} \mathrm{C}$ and relative humidity of $55 \%$ with a turning number of 12 times per day maximizes hatching ratio (90\%) and minimizes loss ratio (12\%) 


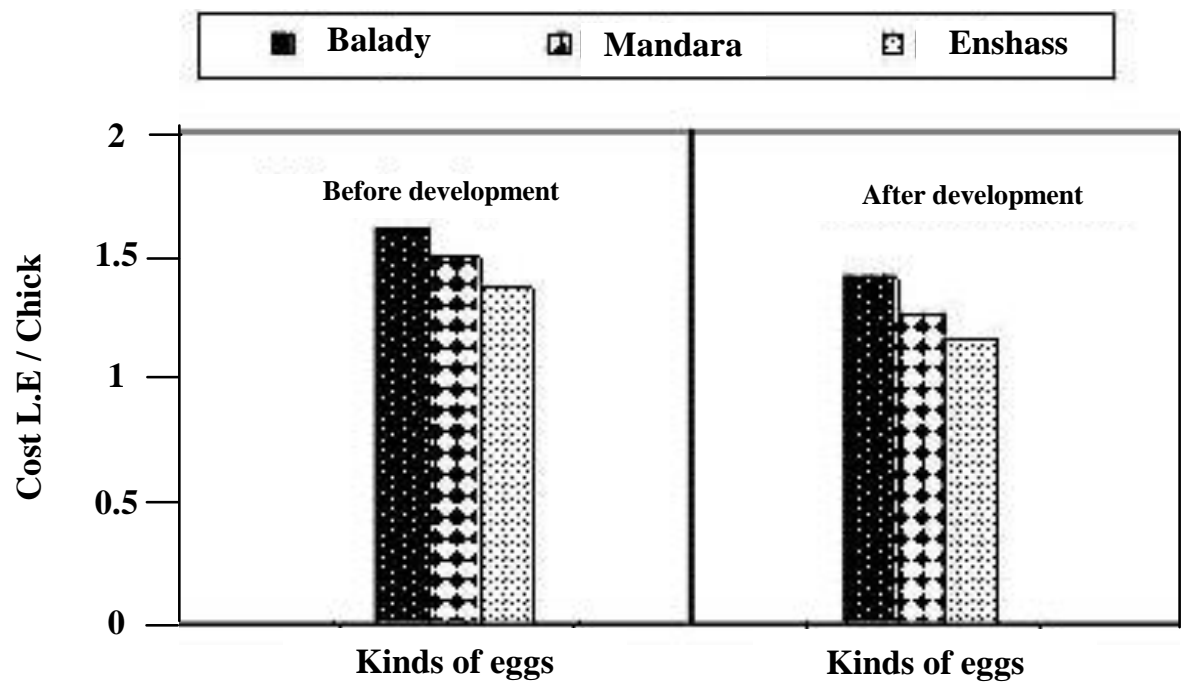

Fig.(12): Hatching cost for local semi- mechanical incubator before and after development using different kinds of eggs .

\section{REFERENCES}

Elibol , O. , and J . Barke (2003) Effect of frequency of turning from three to eleven days of incubation on hatchabibity of broiler hatching eggs . Poultry Sci . $82: 357$ _ 359 .

Fasenko. G.M, V.L Christensen, M.J.Wine Land , and J.N . Petite (2001). Examining the effects of prestorage incubator of turkey breeder eggs or embryonic development and hatchabibtity of eggs stored for four or fourteen days . Poultry Sci . 80 : 132 _136.

Horbanczuk,G.O.,J.Sales,T.Celeda,and G.Zieba(2009) Effect of relative humidity on the hatchability of ostrich (struthio caelus) eggs. Poultry sq.8: 1603-1605.

Hegazy K.E.S.(2000) Improving the performance of eggs poultry local incubation, Misr. J. Ag.Eng. 17(2) : 286-29.

Harun, M.A.S., R.J.Veeneklaas,G.H.Yisser and M.V Kampen (2001). Artifical incubation of muscovy duck eggs, why some eggs hatch and others do not. Poultry sci. 80 :219-224.

Morad, M.M., M.A.Arnaot,A.F.Abd-EL-Mottaleb and S.A.Ghareeb (2008) . Study on some different parameters affecting the efficincy 
of local semi-mechanical incubators. The $15^{\text {th }}$ Annual conference of the Misr socity of Ag. Eng., 12-13 March , 2008 . Vol.25 (2): 555578.

Philadelphia,PA and I.E Febiger(2000).Committee on youth science projects. "list on youth poultry science projects which are available for general distribution." Poultry Science $43: 1616$

Shaapan , E., A., ( 2004 ) . Mechanizing of animal production farms. Unpubl MS.Th, Zigazig, Agric , Egypt .: 93.

\section{الملخص العزبي

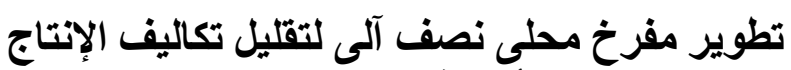

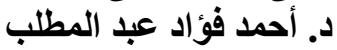

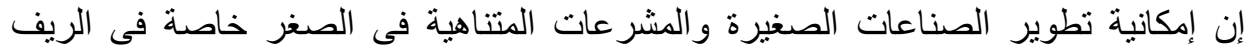

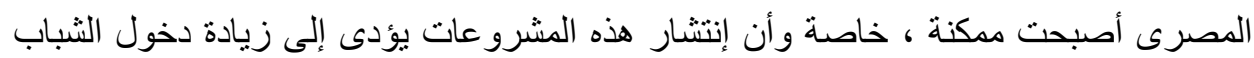

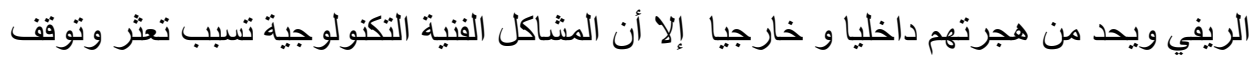

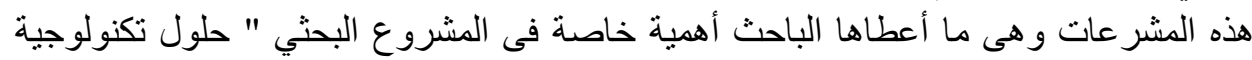

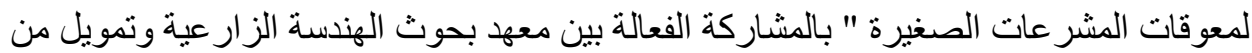

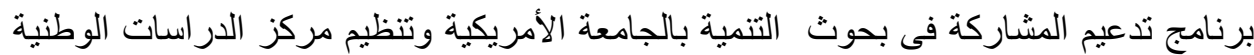

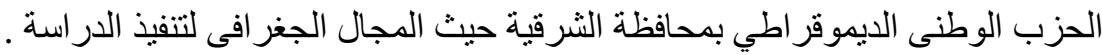

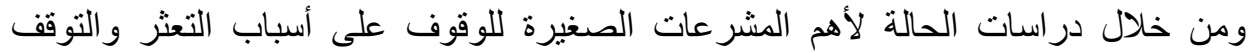

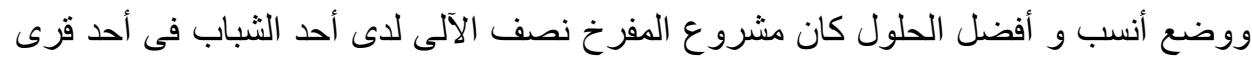

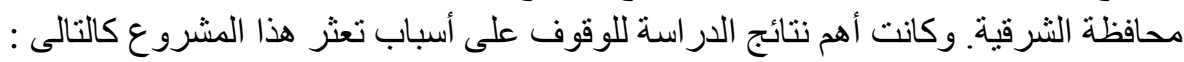

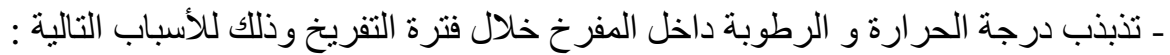

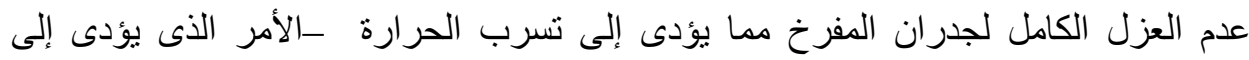

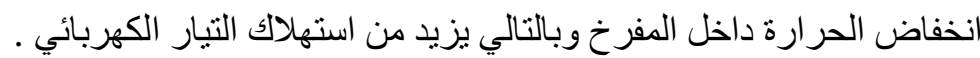

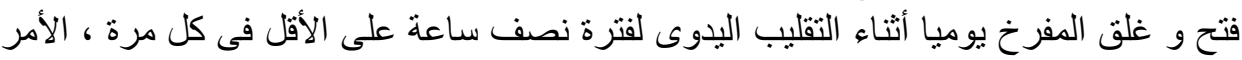

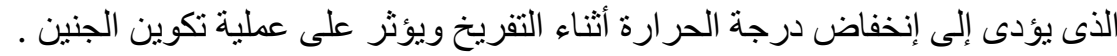

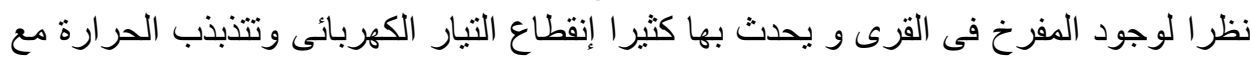

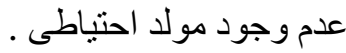

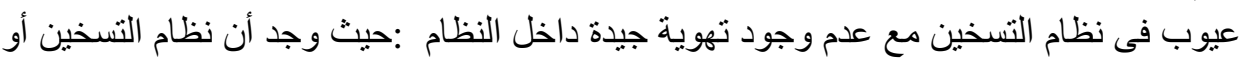

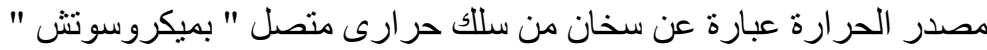

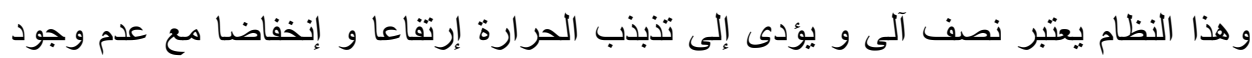

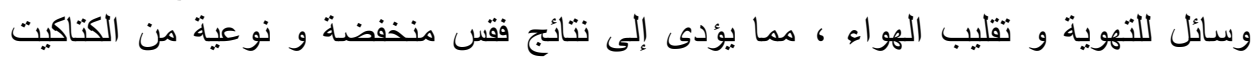

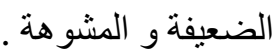

باحث اول ـ معهد بحوث الهندسة الزر اعيةـ قسم بحوث ميكنة عمليات الانتاج الحيو انى ـالدقى - جيزة 


\section{التعديلات التى تمت على المفرخ لحل المشكلات السابقة :-}

لحل مشكلة تذبذب الحر ارة و الرطوبة داخل المفرخ و وأثناء عملية التفريخ :

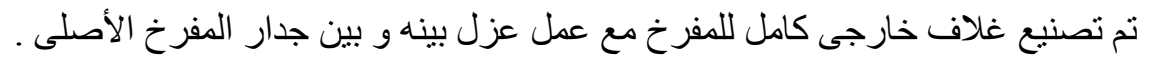

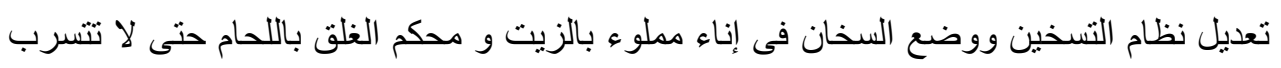

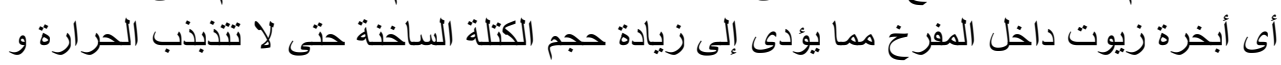

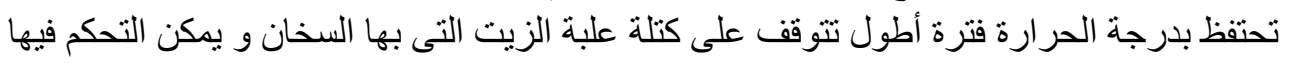

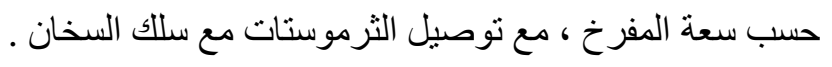

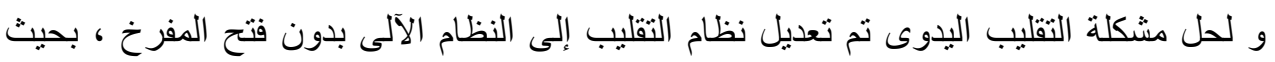

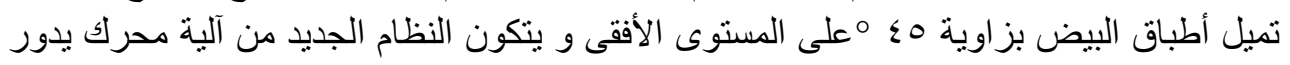

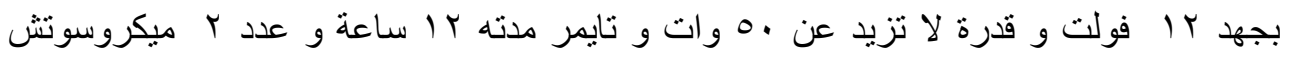

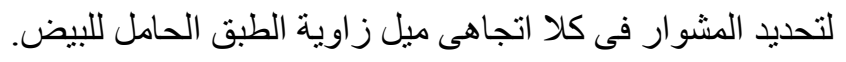
و لمنع التذبذب فى درجة الرطوبة تم عمل التعديل التالى :-

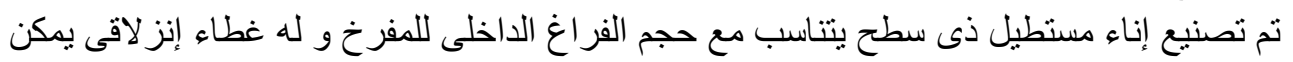

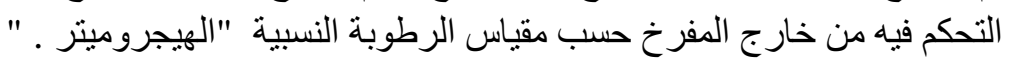
و لزيادة نسبة التهوية داخل المفرخ -

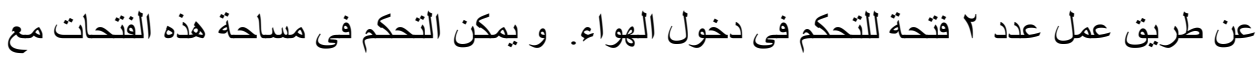

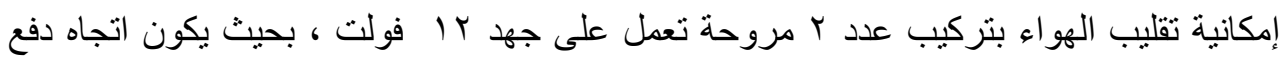

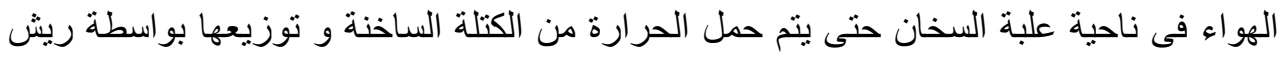

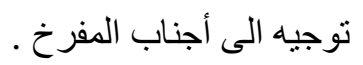

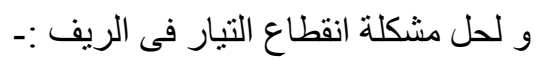

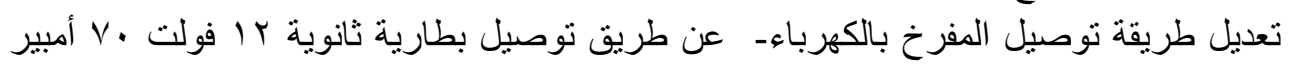

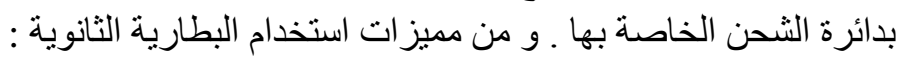

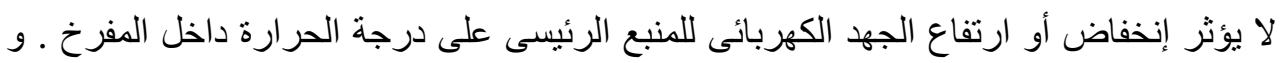

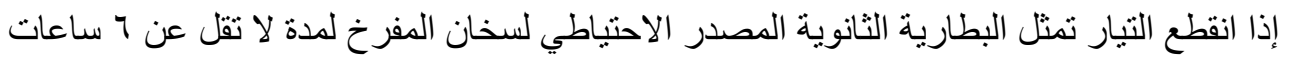

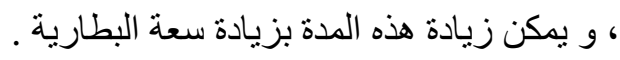

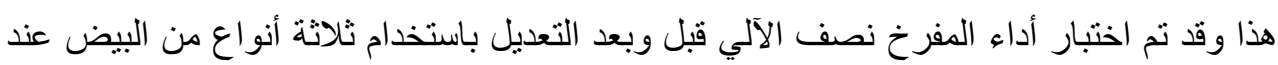

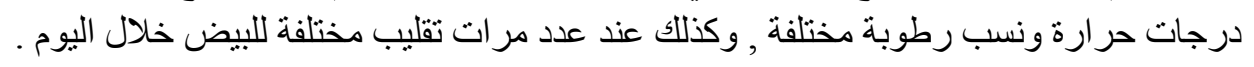

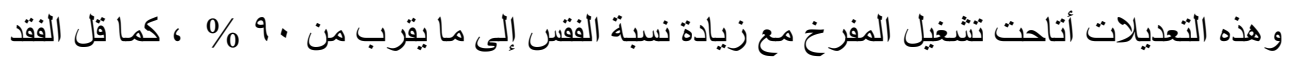

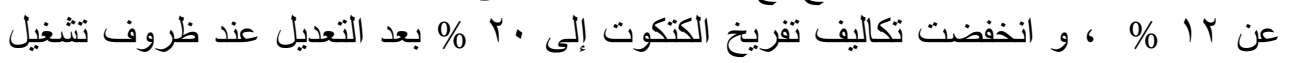

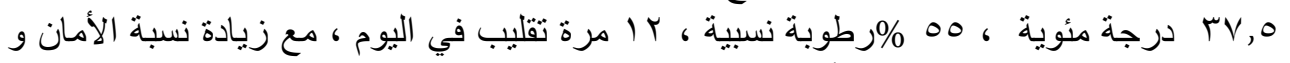

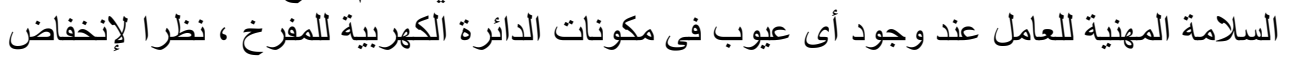

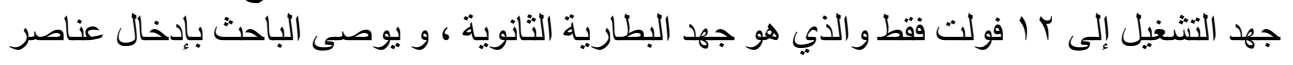

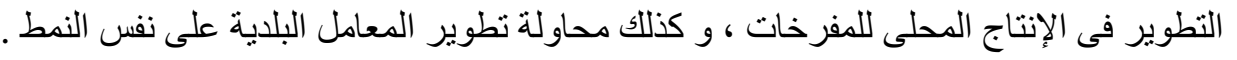

